Manuscript prepared for SOIL

with version 2014/09/16 7.15 Copernicus papers of the $\mathrm{LTT}_{\mathrm{E}} \mathrm{X}$ class copernicus.cls.

Date: 10 September 2015

\title{
Analysis of the linearised observation operator in a soil moisture and temperature analysis scheme
}

\author{
Imtiaz Dharssi ${ }^{1}$, Brett Candy ${ }^{2}$, and Peter Steinle ${ }^{1}$ \\ ${ }^{1}$ Bureau of Meteorology, Melbourne, Australia \\ ${ }^{2}$ Met Office, Exeter, United Kingdom \\ Correspondence to: Imtiaz Dharssi (i.dharssi@bom.gov.au)
}

\begin{abstract}
Several weather forecasting agencies have developed advanced land data assimilation systems that, in principle, can analyse any model land variable. Such systems can make use of a wide variety of observation types, such as screen level (2 meters above the surface) observations and satellite based measurements of surface soil moisture and skin temperature. Indirect measurements can

5 be used and information propagated from the surface into the deeper soil layers. A key component of the system is the calculation of the linearised observation operator matrix (Jacobian matrix) which describes the link between the observations and the land surface model variables. The elements of the Jacobian matrix (Jacobians) are estimated using finite difference by performing short model forecasts with perturbed initial conditions. Analysis is performed of the sensitivity of the calculated
\end{abstract} Jacobians to the magnitude of the perturbations used. The calculated Jacobians show that there can be strong coupling between the sereen level and the soil. The coupling between the sereen level and surface soil moisture is found to be due to a number of processes including bare soil evaporation, soil thermal conductivity as well as transpiration by plants. Therefore, there is significant coupling both during the day and at night. The coupling between the sereen level and root zone soil moisture is primarily through transpiration by plants. Therefore the coupling is only significant during the day and the vertical variation of the coupling is modulated by the vegetation root depths. This Work uses the computed Jacobians to help identify the land surface parameters and processes that most strongly influence data assimilation. In addition, since most land data assimilation systems only assimilate a few observations types, this work uses the computed Jacobians to identify which additional observations types can add the most value. The calculated Jacobians that link screen leveltemperature to model soil temperature are found to be largest for the topmost modelsoil layer and become very small for the lower soil layers. These values are largest during the night and generally positive in value. Results show strong coupling between root zone soil moisture and the 
screen level. While, for the Joint UK Land Environment Simulator (JULES) land surface model, the coupling between the surface and root zone soil moisture is weak. It is found that the Jacobians that link observations of strength of coupling between surface soil moisture to model soil moisture are-and root zone soil moisture is strongly affected by the soil hydraulic conductivity. Generally, for the Joint UK Land Environment Simulator (JULES) land-surface model, the-We suggest that the over-simplified soil hydraulic properties used by most land surface models, including JULES, limits the effectiveness of the assimilation of satellite derived surface soil moisture measurements. Results show strong coupling between the surface and soil moisture and the screen level meaning that assimilation of satellite derived surface soil moisture measurements can be useful for weather forecasting even if the root zone soil moisture is weak. Finally, the Jacobians linking observations of skin temperature to model soil temperature and moistureare calculated. These Jacobians are found to have a similar spatial pattern to the Jacobians for observations of analysis is not significantly improved. Results show strong coupling between root zone soil moisture and skin temperature. Consequently, assimilation of satellite derived skin temperature might significantly improve the analysis of model soil moisture. Finally, results show that observations of both screen level temperature - and satellite derived skin temperature can be used to analyse soil temperature.

Analysis is also performed of the sensitivity of the calculated Jacobians to the magnitude of the perturbations used.

\section{Introduction}

Many observational and modelling studies suggest strong coupling between the atmosphere and the land surface, although with considerable disagreement on the sign of the coupling and magnitude (Koster et al., 2006; Comer and Best, 2012; Taylor et al., 2012; Ford et al., 2015). The land surface states such as soil moisture, temperature and snow play an important role in land-atmosphere coupling. The very high albedo of snow, as well as the water storage and insulation properties means that snow can have a significant impact on numerical weather prediction (NWP) and seasonal forecasting. Soil moisture and temperature have a significant impact on screen level temperature and humidity, low clouds and precipitation, by influencing the exchange of heat and moisture between the land surface and the atmosphere (Schneider et al., 2014; Walker and Rowntree, 1977; Timbal et al., 2002). Soil moisture is important for the prediction of summer-time precipitation at mid-latitudes over land and plays an important role in the development of convective storms (Findell and Eltahir, 1997). The land surface is also very important for the seasonal prediction of extreme events such as heat waves and drought (Weisheimer et al., 2011).

Data assimilation (DA) is extremely important for NWP since errors in the model initial conditions can grow rapidly and seriously degrade forecasts. The initial land surface state can have a significant impact on forecasts of screen level temperature and humidity as well as forecasts of pre- 
cipitation. Specifying the model initial soil moisture and temperature state is especially difficult since there are few near real-time ground based observations of soil moisture and temperature. Therefore, indirect observations are usually used by land surface DA schemes to initialise the model many NWP centres use indirect observations of screen level temperature and humidity to analyse soil moisture and temperature (Dharssiet al., 2011; de Rosnay et al., 2013). The true information content of soil moisture data is in the relative values (such as temporal variations or percent of saturation) and not in the absolute magnitudes (Brocea et al., 2014). Consequently, model soil moisture is highly model specific. For example, Koster et al. (2009) show that direct transfer of soil moisture values from one land surface model to a different land surface model is inappropriate and likely to lead to problems. Therefore, any land surface DA scheme must be consistent with the land surface model used by the NWP system. Inconsistencies in the analysed land surface fields could introduce spurious, long lived shocks to the NWP system and degrade forecasts(a review of land DA methods for NWP is given by de Rosnay et al.., 2014). Recently, a number of space-borne remote sensing systems have been developed to globally observe the land surface state, especially surface soil moisture (recent reviews given by Lakshmi, 2013; Ochsner et al., 2013; Wagner et al., 2 A considerable amount of effort has been committed to develop data assimilation systems capable of using remotely sensed measurements to better understand the hydrological cycle and to improve the initialisation of the land surface state in NWP systems (Munoz-Sabater, 2015; Lahoz and De Lannoy, 2014; Reichle et al. 2014; de I

To make fuller use of the available global remotely sensed measurements of the land surface as well as screen level observations an-a multivariate Extended Kalman Filter (EKF) based land surface data assimilation system has been developed in collaboration between the Bureau of Meteorology (Bureau) and the Met Office (Dharssi et al., 2012). Such EKF land DA systems can make more statistically optimal use of a wide variety of observation types, such as screen level observations and satellite based estimates such as retrieved Surface Soil Moisture, retrieved skin temperature, Leaf Area Index (LAI) and Fraction of Photosynthetically Active Radiation. Indirect measurements can be used and information propagated from the surface into the deeper soil layers. For example an EKF based land DA system may;

- a) Use observations of screen level temperature and humidity to analyse soil temperature and moisture -(e.g. de Rosnay et al., 2013; Mahfouf et al., 2009).

- b) Use satellite estimates of surface soil moisture to analyse surface and root-zone soil moisture -c)(e.g. Draper et al. 2012, 2011; Dharssi et al., 2011; Mahfouf, 2010; Scipal et al., 2008).

- c) Assimilate microwave brightness temperatures to analyse surface and root-zone soil moisture (e.g. Munoz-Sabater, 2015).

- d) Use satellite estimates of skin temperature to analyse soil temperature and moisture A(e.g. Reichle et al., 2010). 
- e) Assimilate satellite estimates of LAI (Rudiger et al., 2010). (e.g. Rudiger et al.. 2010).

This paper uses the EKF land DA system to addresses several challenges related to the use of indirect observations to analyse the land surface variables of interest. In this respect, the relevant science

This paper uses the EKF land DA system
observations to analyse the land surface
questions addressed by this research are:
- 1) What land surface processes an
possible to use observations alone to an
but the models are not perfect. Consequ
several different land surface models. Onl
influence DA. Kumar et al. (2009) use fou
of surface soil moisture and temperature.

- 1) What land surface processes and variables most strongly influence data assimilation? For

Important processes affecting the soil hydraulic properties are neglected by land surface models.

Human activity such as soil tillage practises can cause rapid changes to the upper soil layers (e.g. Wu et al.. 1992).

Drying and freezing of the soil can cause fissures and cracks in the soil. The desiccation, growth and

decay of plant roots as well as activity by soil fauna can also lead to the creation of soil macropores that may significantly enhance the flow of soil water (recent review by Beven and Germann, 2013).

Similarly, most land surface model use Johansen (1975) to parameterise the soil thermal conductivity and ignore important details such as the effects of gravel and soil organic matter (Calvet et al..22015). 
Therefore, it is imperative that much greater priority is given to work examining the role of the soil physical properties on DA.

Question 2 has been addressed before in the scientific literature (e.g. Reichle et al., 2014; Balsamo et al., 2007).

However, this is the first study to use the JULES land surface model to investigate question 2. The use of many different types of observations for land DA is rare. Therefore it is sensible to explore which additional observations types can add the most value to a land DA system.

\section{Land Surface Analysis}

Most NWP centres still only use screen level observations of temperature and humidity for the operational analysis of soil moisture and temperature, e.g. ECMWF (European Centre for Medium range Weather Forecasts; de Rosnay e Meteo-France (Giard and Bazile, 2000) and the German Weather Service (Hess et al., 2008). (see de Rosnay et al.. 2014, and refere The Met Office operationally uses satellite derived measurements of surface soil wetness together with screen level observations for the analysis of soil moisture. Dharssi et al. (2011) find that assimilation of remotely sensed surface soil wetness measurements improves the agreement of the soil moisture analyses with ground based soil moisture observations and improves forecasts of screen level temperature and humidity.

\subsection{The Extended Kalman Filter and Linearised Observation Operator}

The DA problem is kept manageable by assuming that the model land columns are independent of each other (a 1-dimensional approach). This assumption is also made by most land surface models, including JULES (Best et al., 2011). The standard EKF equations for each land column are given by

$\mathbf{x}^{\mathbf{a}}\left(t_{i}\right)=\mathbf{x}^{\mathbf{b}}\left(t_{i}\right)+\mathbf{K}_{i}\left[\mathbf{o}\left(t_{i}\right)-h_{i}\left(\mathbf{x}^{\mathbf{b}}\right)\right]$

$\mathbf{K}_{i}=\mathbf{B} \mathbf{H}_{i}^{T}\left(\mathbf{H}_{i} \mathbf{B} \mathbf{H}_{i}^{T}+\mathbf{R}\right)^{-1}$

$\mathbf{x}\left(t_{i}\right)$ represents the state vector of a land column at time $t_{i}$ with superscripts $a$ and $b$ standing for analysis and background. $\mathbf{o}\left(t_{i}\right)$ is the observation vector. $\mathbf{K}_{i}$ is the Kalman gain matrix at time $t_{i}$. $\mathbf{B}$ is the background error covariance matrix. $\mathbf{R}$ is the observation error covariance matrix.

$\mathbf{H}_{i}$ is the linearised observation operator (Jacobian) matrix and is defined using $h_{i}(\mathbf{x}+\boldsymbol{\Delta}) \simeq$ $h_{i}(\mathbf{x})+\mathbf{H}_{i} \boldsymbol{\Delta}$, where $\boldsymbol{\Delta}$ is a small perturbation to the model state $\mathbf{x}$ and $h_{i}(\mathbf{x})$ is the non-linear observation operator. The elements of $\mathbf{H}_{i}$ (Jacobians) are estimated using finite difference by individually perturbing each component of $\mathbf{x}$ by a a small scalar amount $\delta_{j}$. A given element of $\mathbf{H}_{i}$ is calculated using

$H_{k j}=\frac{y_{k}\left(\mathbf{x}+\delta_{j}\right)-y_{k}(\mathbf{x})}{\delta_{j}}$. 
$y_{k}\left(\mathbf{x}+\delta_{j}\right)$ is a short model forecast of observation type $k$ (e.g. screen level temperature) starting from perturbed initial conditions $\mathbf{x}+\delta_{j}$. The sensitivity of the calculated Jacobians to the magnitude of the perturbations, $\delta$, is described in a later subsection. The number of perturbed forecasts required increases with the number of model variables to be analyses and the number of soil layers. For example, to analyse skin temperature and soil moisture and temperature on four soil levels would require ten perturbed forecasts, including the control $y(\mathbf{x})$. The length of a perturbed forecast is typically a few hours long.

The major computational cost of the EKF land DA system is the cost of running the perturbed forecasts. ECMWF (de Rosnay et al., 2013) use the fully coupled land/atmosphere model for the perturbed forecasts. Meteo France (Mahfouf et al., 2009) use an off-line land surface model (uncoupled to the atmosphere model) for the perturbed forecasts. Consequently the Meteo France EKF land DA system is computationally several orders of magnitude cheaper. The Bureau EKF land DA system also uses an off-line land surface model for the perturbation forecasts. Balsamo et al. (2007) and Mahfouf et al. (2009) have shown that the off line land surface model can be used to reliably calculate $\mathbf{H}_{i}$. The forcing data for the off-line land surface model (precipitation, surface longwave and shortwave radiation, air temperature and humidity, wind speed and surface pressure) are obtained from forecasts of the NWP model. Air temperature and humidity forcing are applied at a height of $20 \mathrm{~m}$ (which is above the screen level). This allows the EKF land DA system to also assimilate observations of screen level temperature and humidity (see Fig. 1 of Mahfouf et al. (2009) for a fuller explanation).

\subsection{The Land Surface Model}

The Bureau EKF land DA system uses JULES to represent the land surface processes. The soil is discretised into four layers of $0.1,0.25,0.65$ and $2 \mathrm{~m}$ thickness (from top to bottom). The soil hydrology is based on a finite difference form of the Richards equation and Darcy's law. The van Genuchten (1980) equations are used to describe the relationship of soil hydraulic conductivity and soil suction to the unfrozen volumetric soil moisture. Currently, there is no vertical variation of the soil hydraulic parameters in the model. The freezing and melting of soil water are also represented and the associated latent heat is included in the thermodynamic calculations.

The JULES model uses 5 vegetation tiles (broadleaf trees, needleleaf trees, C3 (temperate) grass, C4 (tropical) grass and shrubs) and 4 non-vegetation tiles (urban, inland open water, bare soil and land ice). Transpiration by plants extracts soil water directly from the soil layers via the plant roots while bare soil evaporation extracts soil water from the top soil layer only. The ability of plants to access water from each soil layer is determined by the root density distribution and soil moisture availability. The broadleaf trees are assumed to have a root depth of $d_{r}=3 \mathrm{~m}$, needleleaf trees have $d_{r}=1 \mathrm{~m}$, grasses and shrubs have $d_{r}=0.5 \mathrm{~m}$ and the total depth of the model soil $z_{t}=3 \mathrm{~m}$. The bulk stomatal resistance in the absence of soil moisture stress is calculated by a photosynthesis model 
(Mercado et al., 2007) and depends on incident radiation, vegetation type, surface air temperature and humidity deficit. The bulk stomatal resistance includes a dependency on the soil moisture content via a soil moisture availability factor.

\section{Experiments and Results}

In order to avoid compensating effects through temporal averaging, results are presented for one time period only; the off-line perturbed forecasts are started from initial conditions valid at 3Z 16/01/2011. The length of the perturbed forecasts is three hours. Perturbed forecasts with shorter (longer) lengths of one (five) hour(s) have also been tried. Fig. 1 shows the model initial conditions for snow amount and level 1 soil temperature. During January much of the northern hemisphere land is covered by snow. The initial land surface model states (e.g. soil moisture, soil temperature and snow) used in the experiments are obtained from the operational weather forecasting system and are as accurate as possible. Although the model initial conditions are likely to affect the magnitude of the computed Jacobians, they do not affect the conclusions.

\section{3.1 The Jacobians for Screen Level Observations}

Fig. 2 shows an example of the computed Jacobians $H_{T_{2 m}, \theta_{l}} \equiv \Delta T_{2 m} / \Delta \theta_{l}$ which are elements of the linearised observation operator matrix for screen level temperature with respect to soil moisture in the four model soil layers $(l)$. For soil layers two to four, the coupling between screen level temperature and soil moisture is primarily through transpiration by vegetation. Consequently the coupling occurs during daylight. The vertical variation of the coupling is discussed in the next subsection. The negative values means that an increase in soil moisture leads to a cooling of the screen level. For the surface soil layer, the picture is more complicated as there is strong coupling both during the day and at night. The Jacobians have a positive value in some places and a negative value in others.

The Jacobians of screen level specific humidity with respect to soil moisture $\left(\Delta q_{2 m} / \Delta \theta_{l}\right)$ are shown in Fig. 3. The spatial pattern shown in Fig. 3 is similar to Fig. 2. However, for screen level specific humidity, the Jacobian values are primarily positive meaning that an increase in soil moisture leads to an increase in screen level humidity.

The Jacobians of screen level temperature with respect to soil temperature $\left(\Delta T_{2 m} / \Delta T_{l}\right)$ are shown in Fig. 4. The Jacobians are largest for soil level 1 and become very small for soil levels

2253 and 4. The Jacobians are largest during the night and generally positive in value. This is consistent with the experience of ECMWF who find that their soil temperature nudging scheme is more effective during the night and winter when screen level errors are less likely to be related to soil moisture (Mahfouf et al., 2000). 


\subsubsection{Effect of Land Surface Parameterisations}

$245 K_{e}=\left\{\begin{array}{cc}\log _{10} \frac{\theta}{\theta_{s}}+1.0 & \frac{\theta}{\theta_{s}} \geq 0.1 \\ 0 & \text { otherwise }\end{array}\right.$.

pendent of soil moisture,

$\lambda_{s}^{\text {modified }}=\left(\lambda_{\text {sat }}+\lambda_{\text {dry }}\right) / 2$.

Fig. 6 shows $\Delta T_{2 m} / \Delta \theta_{1}$ when the soil thermal conductivity parameterisation is modified and bare soil evaporation is switched off. Comparing Figs. 5 and 6 shows that modifying soil thermal conductivity significantly reduces the coupling between screen level temperature and topmost level soil moisture in many regions, both during the day and night. However, some night-time regions with positive values of $\Delta T_{2 m} / \Delta \theta_{1}$ still persist. This suggests that other processes, such as the relation between soil heat capacity and soil moisture, are also important.

The coupling between the root zone soil moisture and the screen level is primarily through transpiration by plants and is only significant during the day. The vertical variation of the coupling is significantly affected by the vegetation root depths. Fig. 7 shows the computed Jacobians $\Delta T_{2 m} / \Delta \theta_{l}$ when the vegetation root depths are doubled. Increasing the vegetation root depth causes stronger coupling with the deeper soil layers, i.e. increases the magnitude of $\Delta T_{2 m} / \Delta \theta_{4}$ and reduces the magnitude of $\Delta T_{2 m} / \Delta \theta_{2}$. 


\subsection{The Jacobians for the Assimilation of Surface Soil Moisture Measurements}

Several new space-borne remote sensing systems have been developed that provide global retrievals of surface soil moisture (SSM), e.g. SMOS (Soil Moisture Ocean Salinity, Kerr et al., 2001), ASCAT (Advanced SCATterometer, Naeimi et al., 2009) and SMAP (Soil Moisture Active Passive, Entekhabi et al., 2010). Measurements of SSM can be assimilated to update both the model surface and root zone soil moisture by using Equation 3 to compute $\Delta \theta_{1} / \Delta \theta_{l} \equiv H_{\theta_{1}, \theta_{l}}$. Example results are shown in Fig. 8. Generally, for JULES, the coupling between the surface and root zone soil moisture is weak. $\Delta \theta_{1} / \Delta \theta_{3}$ and $\Delta \theta_{1} / \Delta \theta_{4}$ are close to zero. $\Delta \theta_{1} / \Delta \theta_{2}$ is non-zero in regions where the soil is wet and consequently the hydraulic conductivity is high. $\Delta \theta_{1} / \Delta \theta_{1} \equiv H_{\theta_{1}, \theta_{1}}$ is close to unity in most regions, the exceptions are where the soil is wet and Jacobian values as low as 0.5 can occur. Increasing the length of the perturbation forecasts is found to significantly increase the coupling between the surface and root zone soil moisture. Draper (2011) has also found similar results when using JULES. The modelling study of Capehart and Carlson (1997) has already recognised that the SSM can become decoupled from root zone soil moisture. Pessimistically, Capehart and Carlson (1997) conclude that "soil moisture derived from surface radiant temperatures is probably not useful in knowing the column-average soil water content".

The van Genuchten (1980) equations JULES, uses the van Genuchten (1980) equations to describe the relationship between the soil hydraulic conductivity $\left(K_{V G}\right)$ and the unfrozen volumetric soil moisture $\theta^{u}$.

$K_{V G}=K_{s} S_{e}^{L}\left[1-\left(1-S_{e}^{1 / m}\right)^{m}\right]^{2}$

where the soil wetness $S_{e}=\left(\theta^{u}-\theta_{r}\right) /\left(\theta_{s}-\theta_{r}\right), L=0.5$ and $m=1-1 / n . \theta_{s}, \theta_{r}, K_{s}, \alpha$ and $n$ are the van Genuchten soil parameters and assumed to depend on soil type. (VG) soil parameters. The JULES VG soil parameters are derived from soil texture maps (e.g. Miller and White, 1998; FAO et al., 2008) and pedotransfer functions (e.g. Cosby et al., 1984). Ideally the JULES VG parameters would agree closely with measured values. However the very high spatial variability of soil texture as well as uncertainties in soil texture maps (e.g. Brus et al., 2011; Hartemink et al., 2013; Marthews et al., 2014; Bandara et al., 2015) and pedotransfer functions lead to significant errors. Cosby et al. (1984); Schaap and Leij (1998) show that the uncertainty in predicted $K_{s}$ is about one order of magnitude. The hydraulic conductivity is also very sensitive to changes in soil moisture. Small changes in soil moisture can lead to order of magnitude changes in soil hydraulic conductivity. For example, when $S_{e}=1, K_{V G}=K_{s}$ while when $S_{e}=0.9$ and $n=1.18, K_{V G}=K_{s} \times 10^{-2}$ (i.e. a $10 \%$ decrease in soil wetness leads to a two orders of magnitude decrease in soil hydraulic conductivity). In addition, $K_{S}$ is strongly affected by soil type and has a high spatial variability (see for example Marthews et al., 2014; Bandara et al., 2015). For coarse textured soils the model assumes $K_{s}=1.95 \times 10^{-2} \mathrm{~mm} / \mathrm{s}$ while for medium textured in predicted $K_{s}$ is about one order of magnitude. Consequently, uncertainty in soil type and pedotransfer 
functions can also lead to-at least order of magnitude uncertainty in is expected in the modelled soil hydraulic conductivity.

Fig. 9 shows the computed Jacobians $\Delta \theta_{1} / \Delta \theta_{2}$ when the soil hydraulic conductivity is increased by a factor of ten. The coupling between the SSM and the root zone has increased significantly.

Using four different land surface models with different coupling strengths and synthetic observations of SSM, Kumar et al. (2009) find that the potential of SSM assimilation to improve root zone soil moisture is higher when the coupling between the SSM and root zone soil moisture is stronger. The crucial point is that this work shows that the soil hydraulic conductivity significantly influences the assimilation of measurements of SSM. Until now, the importance of the soil hydraulic conductivity for data assimilation has received little recognition. Moreover, important processes affecting the soil hydraulic properties and particularly the soil hydraulic conductivity are neglected by land surface models. Given that the true strength of coupling between the SSM and root zone soil moisture is unknown, the non-identical twin, assimilation experiments of Kumar et al. (2009) suggest that it is better to over-estimate rather than under-estimate the coupling between the SSM and root zone soil moisture. Therefore, we suggest artificially increasing the model soil hydraulic conductivity by a factor of ten may be an effective technique to improve the assimilation of satellite derived SSMimprove DA skill. Such a tactic could be justified on the grounds of compensating for missing soil processes in the model; such as preferential water flow through soil macropores (Beven and Germann, 2013).

315 However, careful and comprehensive testing will be required to fully validate all the consequences of such an approach.

\subsection{The Jacobians of the Observation Operator for Surface Skin Temperature}

Best and Maisey (2002) show that in unstable conditions, to a good approximation

$\Delta T_{*}=\Delta T_{2 m} /\left(1-\mu r_{a, 2 m} / r_{a}\right)$

Where $r_{a}\left(r_{a, 2 m}\right)$ is the aerodynamic resistance between the surface and first model level (screen level) and $\mu \simeq 0.9$. Therefore, it is expected that the computed Jacobians between surface skin temperature and soil moisture $\left(\Delta T_{*} / \Delta \theta_{l}\right)$ should show a similar spatial pattern to the Jacobians between screen level temperature and soil moisture $\left(\Delta T_{2 m} / \Delta \theta_{l}\right)$ but have a larger magnitude (since the denominator in Eq 8 is less than 1). Fig. 10 shows the computed Jacobians $\Delta T_{*} / \Delta \theta_{l}$ and that there is significant coupling between surface skin temperature and soil moisture. Therefore, it may be possible to assimilate satellite measurements of $T_{*}$ to analyse soil moisture. However, for a variety of reasons, model and satellite derived surface skin temperature exhibit very different climatologies and consequently bias correction will be required (Reichle et al., 2010). As expected, comparing Figs. 10 and 2 shows that, the spatial variation of $\Delta T_{*} / \Delta \theta_{l}$ is very similar to $\Delta T_{2 m} / \Delta \theta_{l}$ and the magnitudes are much larger. Fig. 11 shows the computed Jacobians $\Delta T_{*} / \Delta T_{l}$ and that there is significant coupling between surface skin temperature and model level 1 soil temperature. There are also strong 
similarities between $\Delta T_{*} / \Delta T_{l}$ and $\Delta T_{2 m} / \Delta T_{l}$. Ghent et al. (2010) have assimilated measurements of surface skin temperature for the Africa region using the JULES land surface model and found improvements to model surface fluxes and soil moisture.

\subsection{Sensitivity to Magnitude of Perturbations}

Fig. 12 shows the sensitivity of the calculated Jacobians for screen level temperature to the magnitude of the volumetric soil moisture perturbations, for the Australia region. The results indicates that the system is well behaved for perturbation values in the range of $10^{-4}$ to $10^{-2} \mathrm{~m}^{3} / \mathrm{m}^{3}$, a perturbation value of $10^{-3} \mathrm{~m}^{3} / \mathrm{m}^{3}$ is found to be close to optimal. A similar analysis using the calculated Jacobians for screen level specific humidity also shows that a soil moisture perturbation value of $10^{-3} \mathrm{~m}^{3} / \mathrm{m}^{3}$ is close to optimal (results not shown). The Jacobians for screen level specific humidity are less sensitive to the magnitude of the soil moisture perturbation. For skin and soil temperature, results indicate that the system is well behaved for perturbation values in the range of $10^{-2}$ to $1 \mathrm{~K}$, a perturbation value of $10^{-1} \mathrm{~K}$ is found to be close to optimal.

\section{Conclusions}

To take full advantage of the available global satellite measurements of the land surface as well as screen level observations an EKF based land surface data assimilation system has been developed at the Bureau in collaboration with the Met Office. Such a system is flexible and can make more statistically optimal use of a wide variety of observation types. The most important aspect of the system is the calculation of the Jacobians that describe the link between the observations and the land surface model variables. The Jacobians are computed using finite difference by perturbing each model variable to be analysed, in-turn, and performing short model forecasts. The number of perturbed forecasts required increases with the number of model variables to be analyses and the number of soil layers. Other works such as Mahfouf et al. (2009) and Drusch et al. (2009) have also looked at the calculation of the Jacobians. However, this work examines the Jacobians in much greater detail than before. In addition, this is the first work to use the JULES land surface model to compute the Jacobians for screen level observations and measurements of surface skin temperature.

Results show that the computed Jacobians can be sensitive to the size of the perturbations used. Perturbations that are too small cause problems due to numerical rounding while perturbations that are too large cause problems due to non-linearities in the model. Experiments show that volumetric soil moisture perturbation values in the range of $10^{-4}$ to $10^{-2} \mathrm{~m}^{3} / \mathrm{m}^{3}$ give good results and a perturbation value of $10^{-3} \mathrm{~m}^{3} / \mathrm{m}^{3}$ is close to optimal. For skin and soil temperature perturbations, experiments indicate that a perturbation value of $10^{-1} \mathrm{~K}$ is close to optimal.

This is the first work to look at the effect of land surface parameterisations on the computed Jacobians and consequently DA. As expected, the parameterisation details have a significant impact. 
Experiments are performed where the parameterisations are modified or switched off. Results show that the there can be strong coupling between the soil moisture in the topmost model layer and the screen level is screen level and the soil. The coupling between the screen level and surface soil moisture is found to be due to a number of processes including bare soil evaporation, soil thermal conductivity, soil thermal capacity as well as transpiration by plants. Therefore, there is significant coupling both during the day and at night. The coupling between the soil moisture in the lower model layers and the sereen level is due to-screen level and root-zone soil moisture is primarily through transpiration by plants. This result is significant as it explains why the coupling with the soit moisture in the topmost model layer is much stronger than the coupling with the soil moisture in the lower model layers. Consequently, soil moisture increments in the topmost model layer will be larger than would be the case if the coupling were only due to transpiration. In addition, improving the analysis of topmest model layer soil moisture will have a signifieant impact on forecasts of sereen level temperature and humidity.

The Jacobians linking observations of surface soil moisturewith soil moisture in the lower model tayers have been computed. Experiments show that artificially increasing the soil hydratlic conductivity by a factor of ten significantly increases the couplingbetween the surface and Therefore the coupling is only significant during the day and the vertical variation of the coupling is modulated by the vegetation root depths. Results also show strong coupling between screen level temperature and upper level soil temperature during the night. Results show strong coupling between skin temperature and both soil moisture and soil temperature. The spatial pattern of this coupling is very similar to the coupling between the screen level and the soil.

The experiment results are not surprising, nor should they be. Surprising results would imply errors in the model or DA scheme. These types of experiments could also be used as part of the validation procedure for land surface models and land DA systems. Careful consideration of the experiment results shows that there is much more to land DA than just the assimilation of satellite derived measurements of SSM. The experiments show that screen level observations and satellite derived skin temperature measurements can also be assimilated to analyse root zone soil moisture. Moreover, the results show that while root zone soil moisture is very important, other land surface variables are also important for land-atmosphere coupling.

395 Results show strong coupling between root zone soil moisture - Otherwiseand the screen level. However, for JULES, the coupling between the surface and-root zone soil moisture and SSM is weak. Small uncertainty in soil moisture or soil type can lead to order of magnitude uncertainty in soil hydraulic conductivity. In addition, Kumar et al. (2009) suggest that it is better to over estimate rather than under-estimate the This result is consistent with other DA studies (using various land surface models) which show that SSM measurements provides a much weaker constraint of the root zone soil moisture than the screen level observations (de Rosnay et al..2013; Draper et al.,2011; Dharssi et al., 2011; Scipal et al., 2 This helps to explain why so many NWP centres continue to choose to operationally assimilate 
screen level temperature and humidity observations to analyse soil moisture. Soil moisture validation studies such as Albergel et al. (2012); Vinodkumar et al. (2015) find good agreement between ground based soil moisture observations and DA analyses when screen level observations are assimilated. However, the sparsity of screen level observations in many parts of the world means that is highly desirable to also assimilate remotely sensed observations. Results show strong coupling between the surface and soil moisture in the topmost model layer and the screen level. This result is significant as it shows that assimilation of SSM measurements can be useful for weather forecasting even if the root zone soil moisture . Consequently, artificially increasing the model analysis is not significantly improved. Experiments show that the model parameterisation of soil hydraulic conductivity by a factor of ten may be an effective technique to improve-strongly affects the assimilation of SSM measurements. Therefore, we postulate that the over-simplified soil hydraulic properties used by most land surface models, including JULES, limits the effectiveness of the assimilation of satellite derived surface soil moistureSSM measurements.

The Jacobians linking observations of skin temperature to model soil temperature and moisture have also been computed. These Jacobians have a similar spatial pattern to the Jacobians linking observations of Experiments show strong coupling between root zone soil moisture and skin temperature. Therefore, we intend to prioritise the assimilation of satellite derived skin temperature. In addition, results show that observations of both screen level temperature to model soil temperature and moisture but are larger in magnitude. Consequently, assimilation of and satellite derived skin temperature may atso significantly improve the analysis of model soil temperatureand moisture. can be used to analyse soil temperature.

It is well known that model soil moisture is model specific (Koster et al., 2009). Results indicate that the Jacobians are also model specific. Consequently, careful examination of the Jacobians might allow significant insight into the behaviour of land surface models. It is intended that the CABLE land surface model (Kowalczyk et al., 2013) will be integrated into the JULES framework (Law et al., 2012). Therefore, it would be instructive to examine and compare the Jacobians computed using CABLE, JULES and other land surface models.

Acknowledgements. Parts of this work have been previously published as a technical report. (Dharssi et al., 2012). Since publication of the technical report major effort has been committed to develop an operational system that runs every few hours in near real-time to analyse soil moisture using screen level observations and satellite derived SSM measurements.

Thanks go to Toby Marthews and Anne Verhoef as well as two anonymous reviewers for helping to significantly improve the manuscript. 


\section{References}

Albergel, C., de Rosnay, P., Gruhier, C., Muñoz-Sabater, J., Hasenauer, S., Isaksen, L., Kerr, Y., and Wagner, W.: Evaluation of remotely sensed and modelled soil moisture products using global ground-based in situ observations, Remote Sensing of Environment, 118, 215-226, 2012.

Balsamo, G., Mahfouf, J., Bélair, S., and Deblonde, G.: A land data assimilation system for soil moisture and temperature: an information content study, Journal of Hydrometeorology, 8, 1225-1242, doi:10.1175/2007JHM819.1, 2007.

Bandara, R., Walker, J. P., Rüdiger, C., and Merlin, O.: Towards soil property retrieval from space: An application with disaggregated satellite observations, Journal of Hydrology, 522, 582 593, doi:http://dx.doi.org/10.1016/j.jhydrol.2015.01.018, http://www.sciencedirect.com/science/article/pii/ S0022169415000359, 2015.

Best, M. and Maisey, P.: A physically based soil moisture nudging scheme, Hadley Centre Technical Note 35, Met. Office, Exeter, UK, 2002.

Best, M., Abramowitz, G., Johnson, H., Pitman, A., Balsamo, G., Boone, A., Cuntz, M., Decharme, B., Dirmeyer, P., Dong, J., Ek, M., Guo, Z., Haverd, V., van den Hurk, B. J. J., Nearing, G. S., Pak, B., PetersLidard, C., Santanello, J. A., Stevens, L., and Vuichard, N.: The plumbing of land surface models: benchmarking model performance, Journal of Hydrometeorology, doi:10.1175/JHM-D-14-0158.1, 2015.

Best, M. J., Pryor, M., Clark, D. B., Rooney, G. G., Essery, R. L. H., Ménard, C. B., Edwards, J. M., Hendry, M. A., Porson, A., Gedney, N., Mercado, L. M., Sitch, S., Blyth, E., Boucher, O., Cox, P. M., Grimmond, C. S. B., and Harding, R. J.: The Joint UK Land Environment Simulator (JULES), model description - Part 1: Energy and water fluxes, Geoscientific Model Development, 4, 677-699, doi:10.5194/gmd-4-677-2011, http://www.geosci-model-dev.net/4/677/2011/, 2011.

Beven, K. and Germann, P.: Macropores and water flow in soils revisited, Water Resources Research, 49, 30713092, doi:10.1002/wrcr.20156, http://dx.doi.org/10.1002/wrcr.20156, 2013.

Brocca, L., Zucco, G., Mittelbach, H., Moramarco, T., and Seneviratne, S. I.: Absolute versus temporal anomaly and percent of saturation soil moisture spatial variability for six networks worldwide, Water Resources Research, 50, 5560-5576, doi:10.1002/2014WR015684, http://dx.doi.org/10.1002/2014WR015684, 2014.

Brooks, R. and Corey, A.: Hydraulic properties of porous media, Hydrology Papers. Colorado State University $(, 1964$.

Brus, D., Kempen, B., and Heuvelink, G.: Sampling for validation of digital soil maps, European Journal of Soil Science, 62, 394-407, doi:10.1111/j.1365-2389.2011.01364.x, http://dx.doi.org/10.1111/j.1365-2389.2011. 01364.x, 2011.

Calvet, J.-C., Fritz, N., Berne, C., Piguet, B., Maurel, W., and Meurey, C.: Impact of gravels and organic matter on the thermal properties of grassland soils in southern France, SOIL Discussions, 2, 737-765, doi:10.5194/soild-2-737-2015, http://www.soil-discuss.net/2/737/2015/, 2015.

Campbell, G.: A simple method for determining unsaturated conductivity from moisture retention data, Soil Science, 117, 311, 1974.

Capehart, W. J. and Carlson, T. N.: Decoupling of surface and near-surface soil water content: A remote sensing perspective, Water Resources Research, 33, 1383-1395, doi:10.1029/97WR00617, http://dx.doi.org/10. 1029/97WR00617, 1997. 
Comer, R. E. and Best, M. J.: Revisiting GLACE: Understanding the Role of the Land Surface in LandAtmosphere Coupling, Journal of Hydrometeorology, 13, 1704-1718, 2012.

Cosby, B., Hornberger, G., Clapp, R., and Ginn, T.: A statistical exploration of the relationships of soil moisture characteristics to the physical properties of soils, Water Resources Research, 20, 682-690, 1984.

de Rosnay, P., Drusch, M., Vasiljevic, D., Balsamo, G., Albergel, C., and Isaksen, L.: A simplified Extended Kalman Filter for the global operational soil moisture analysis at ECMWF, Quarterly Journal of the Royal Meteorological Society, 139, 1199-1213, doi:10.1002/qj.2023, http://dx.doi.org/10.1002/qj.2023, 2013.

de Rosnay, P., Balsamo, G., Albergel, C., Muñoz-Sabater, J., and Isaksen, L.: Initialisation of Land Surface Variables for Numerical Weather Prediction, in: The Earth's Hydrological Cycle, edited by Bengtsson, L., Bonnet, R.-M., Calisto, M., Destouni, G., Gurney, R., Johannessen, J., Kerr, Y., Lahoz, W., and Rast, M., vol. 46 of Space Sciences Series of ISSI, pp. 607-621, Springer Netherlands, doi:10.1007/978-94-017-87895_7, http://dx.doi.org/10.1007/978-94-017-8789-5_7, 2014.

Dharssi, I., Vidale, P., Verhoef, A., Macpherson, B., Jones, C., and Best, M.: New soil physical properties implemented in the Unified Model at PS18, Meteorology Research and Development Technical Report 528, Met. Office, Exeter, UK, http://tinyurl.com/UKMOreport528-pdf, 2009.

Dharssi, I., Bovis, K. J., Macpherson, B., and Jones, C. P.: Operational assimilation of ASCAT surface soil wetness at the Met Office, Hydrology and Earth System Sciences, 15, 2729-2746, doi:10.5194/hess-152729-2011, http://www.hydrol-earth-syst-sci.net/15/2729/2011/, 2011.

Dharssi, I., Steinle, P., and Candy, B.: Towards a Kalman Filter based land surface data assimilation scheme for ACCESS, CAWCR Technical Report 54, The Centre for Australian Weather and Climate Research, Melbourne, Australia, http://www.cawcr.gov.au/publications/technicalreports/CTR_054.pdf, 2012.

Draper, C.: Near-surface Soil Moisture Assimilation in NWP, Ph.D. thesis, Department of Civil and Environmental Engineering, University of Melbourne, Parkville, Australia, http://users.monash.edu.au/ jpwalker/ theses/ClaraDraper.pdf, 2011.

Draper, C. S., Mahfouf, J.-F., and Walker, J. P.: Root zone soil moisture from the assimilation of screenlevel variables and remotely sensed soil moisture, Journal of Geophysical Research: Atmospheres, 116, doi:10.1029/2010JD013829, http://dx.doi.org/10.1029/2010JD013829, d02127, 2011.

Draper, C. S., Reichle, R. H., De Lannoy, G. J. M., and Liu, Q.: Assimilation of passive and active microwave soil moisture retrievals, Geophysical Research Letters, 39, doi:10.1029/2011GL050655, http://dx.doi.org/10. 1029/2011GL050655, 104401, 2012.

Drusch, M., Scipal, K., de Rosnay, P., Balsamo, G., Andersson, E., Bougeault, P., and Viterbo, P.: Towards a Kalman Filter based soil moisture analysis system for the operational ECMWF Integrated Forecast System, Geophysical Research Letters, 36, doi:10.1029/2009GL037716, http://dx.doi.org/10.1029/2009GL037716, 110401, 2009.

510 Entekhabi, D., Njoku, E. G., O’Neill, P. E., Kellogg, K. H., Crow, W. T., Edelstein, W. N., Entin, J. K., Goodman, S. D., Jackson, T. J., Johnson, J., Kimball, J., Piepmeier, J., Koster, R., Martin, N., McDonald, K., Moghaddam, M., Moran, S., Reichle, R., Shi, J.-C., Spencer, M., Thurman, S., Tsang, L., and Van Zyl, J.: The soil moisture active passive (SMAP) mission, Proceedings of the IEEE, 98, 704-716, 2010.

FAO, IIASA, ISRIC, ISS-CAS, and JRC: Harmonised world soil database (version 1.0), Tech. rep., FAO, Rome, Italy and IIASA, Laxenburg, Austria, 2008. 
Findell, K. and Eltahir, E.: An analysis of the soil moisture-rainfall feedback, based on direct observations from Illinois, Water Resources Research, 33, 725-735, 1997.

Ford, T. W., Rapp, A. D., Quiring, S. M., and Blake, J.: Soil moisture-precipitation coupling: observations from the Oklahoma Mesonet and underlying physical mechanisms, Hydrology and Earth System Sciences Discussions, 12, 3205-3243, doi:10.5194/hessd-12-3205-2015, http://www.hydrol-earth-syst-sci-discuss.net/ 12/3205/2015/, 2015.

Ghent, D., Kaduk, J., Remedios, J., Ardo, J., and Balzter, H.: Assimilation of land surface temperature into the land surface model JULES with an ensemble Kalman filter, Journal of Geophysical Research: Atmospheres, 115, doi:10.1029/2010JD014392, http://dx.doi.org/10.1029/2010JD014392, d19112, 2010.

Giard, D. and Bazile, E.: Implementation of a new assimilation scheme for soil and surface variables in a global NWP model, Monthly Weather Review, 128, 997-1015, 2000.

Hartemink, A. E., Krasilnikov, P., and Bockheim, J.: Soil maps of the world, Geoderma, 207-208, 256 - 267, doi:http://dx.doi.org/10.1016/j.geoderma.2013.05.003, http://www.sciencedirect.com/science/article/ pii/S0016706113001572, 2013.

530 Hess, R., Lange, M., and Wergen, W.: Evaluation of the variational soil moisture assimilation scheme at Deutscher Wetterdienst, Quarterly Journal of the Royal Meteorological Society, 134, 1499-1512, doi:10.1002/qj.306, http://dx.doi.org/10.1002/qj.306, 2008.

Johansen, O.: Thermal conductivity of soils, Ph.D. thesis, University of Trondheim, Norway, 1975.

Kerr, Y., Waldteufel, P., Wigneron, J., Martinuzzi, J., Font, J., and Berger, M.: Soil moisture retrieval from space: The Soil Moisture and Ocean Salinity (SMOS) mission, IEEE Transactions on Geoscience and Remote Sensing, 39, 1729-1735, doi:10.1109/36.942551, 2001.

Koster, R., Guo, Z., Yang, R., Dirmeyer, P., Mitchell, K., and Puma, M.: On the nature of soil moisture in land surface models, Journal of Climate, 22, 4322-4335, 2009.

Koster, R. D., Sud, Y. C., Guo, Z., Dirmeyer, P. A., Bonan, G., Oleson, K. W., Chan, E., Verseghy, D., Cox, P., Davies, H., Kowalczyk, E., Gordon, C. T., Kanae, S., Lawrence, D., Liu, P., Mocko, D., Lu, C.-H., Mitchell, K., Malyshev, S., McAvaney, B., Oki, T., Yamada, T., Pitman, A., Taylor, C. M., Vasic, R., and Xue, Y.: GLACE: The Global Land Atmosphere Coupling Experiment. Part I: Overview, Journal of Hydrometeorology, 7, 590-610, doi:10.1175/JHM510.1, http://journals.ametsoc.org/doi/abs/10.1175/JHM510.1, 2006.

Kowalczyk, E., Stevens, L., Law, R., Dix, M., Wang, Y., Harman, I., Haynes, K., Srbinovsky, J., Pak, B., and Ziehn, T.: The land surface model component of ACCESS: description and impact on the simulated surface climatology, Australian Meteorological and Oceanographic Journal, 63, 65-82, 2013.

Kumar, S. V., Reichle, R. H., Koster, R. D., Crow, W. T., and Peters-Lidard, C. D.: Role of Subsurface Physics in the Assimilation of Surface Soil Moisture Observations, Journal of Hydrometeorology, 10, 1534-1547, doi:10.1175/2009JHM1134.1, http://journals.ametsoc.org/doi/abs/10.1175/2009JHM1134.1, 2009.

Lahoz, W. A. and De Lannoy, G. J.: Closing the Gaps in Our Knowledge of the Hydrological Cycle over Land: Conceptual Problems, in: The Earth's Hydrological Cycle, edited by Bengtsson, L., Bonnet, R.-M., Calisto, M., Destouni, G., Gurney, R., Johannessen, J., Kerr, Y., Lahoz, W., and Rast, M., vol. 46 of Space Sciences Series of ISSI, pp. 623-660, Springer Netherlands, doi:10.1007/978-94-017-8789-5_8, http://dx.doi.org/10. 1007/978-94-017-8789-5_8, 2014.

555 Lakshmi, V.: Remote Sensing of Soil Moisture, ISRN Soil Science, 2013, doi:10.1155/2013/424178, 2013. 
Law, R., Raupach, M., Abramowitz, G., Dharssi, I., Haverd, V., Pitman, A., Renzullo, L., Van Dijk, A., and Wang, Y. P.: CABLE RoadMap 2012-2017, CAWCR Technical Report, The Centre for Australian Weather and Climate Research, Australia, 2012.

Mahfouf, J.: Assimilation of satellite-derived soil moisture from ASCAT in a limited-area NWP model, Quarterly Journal of the Royal Meteorological Society, 136, 784-798, doi:10.1002/qj.602, 2010.

Mahfouf, J., Viterbo, P., Douville, H., Beljaars, A., and Saarinen, S.: A revised land-surface analysis scheme in the integrated forecasting system, ECMWF newsletter, 88, 8-13, old.ecmwf.int/publications/newsletters/ pdf/88.pdf, 2000.

Mahfouf, J.-F., Bergaoui, K., Draper, C., Bouyssel, F., Taillefer, F., and Taseva, L.: A comparison of two offline soil analysis schemes for assimilation of screen level observations, Journal of Geophysical Research: Atmospheres, 114, doi:10.1029/2008JD011077, http://dx.doi.org/10.1029/2008JD011077, d08105, 2009.

Marthews, T. R., Quesada, C. A., Galbraith, D. R., Malhi, Y., Mullins, C. E., Hodnett, M. G., and Dharssi, I.: High-resolution hydraulic parameter maps for surface soils in tropical South America, Geoscientific Model Development, 7, 711-723, doi:10.5194/gmd-7-711-2014, http://www.geosci-model-dev.net/7/711/ 2014/, 2014.

Mercado, L., Huntingford, C., Gash, J., Cox, P., and Jogireddy, V.: Improving the representation of radiation interception and photosynthesis for climate model applications, Tellus B, 59, 553-565, 2007.

Miller, D. and White, R.: A conterminous United States multilayer soil characteristics dataset for regional climate and hydrology modeling, Earth Interactions, 2, 1-26, doi:10.1175/10873562(1998)002<0001:ACUSMS>2.3.CO;2, 1998.

Munoz-Sabater, J.: Incorporation of Passive Microwave Brightness Temperatures in the ECMWF Soil Moisture Analysis, Remote Sensing, 7, 5758, doi:10.3390/rs70505758, http://www.mdpi.com/2072-4292/7/5/5758, 2015.

Naeimi, V., Scipal, K., Bartalis, Z., Hasenauer, S., and Wagner, W.: An improved soil moisture retrieval algorithm for ERS and METOP scatterometer observations, IEEE transactions on geoscience and remote sensing, 47, 1999-2013, doi:10.1109/TGRS.2008.2011617, 2009.

Ochsner, T. E., Cosh, M. H., Cuenca, R. H., Dorigo, W. A., Draper, C. S., Hagimoto, Y., Kerr, Y. H., Njoku, E. G., Small, E. E., and Zreda, M.: State of the art in large-scale soil moisture monitoring, Soil Science Society of America Journal, 77, 1888-1919, 2013.

Peters-Lidard, C., Blackburn, E., Liang, X., and Wood, E.: The effect of soil thermal conductivity parameterization on surface energy fluxes and temperatures, Journal of the Atmospheric Sciences, 55, 1209-1224, 1998.

Reichle, R. H., Kumar, S. V., Mahanama, S. P., Koster, R. D., and Liu, Q.: Assimilation of satellite-derived skin temperature observations into land surface models, Journal of Hydrometeorology, 11, 1103-1122, 2010.

Reichle, R. H., De Lannoy, G. J., Forman, B. A., Draper, C. S., and Liu, Q.: Connecting Satellite Observations with Water Cycle Variables Through Land Data Assimilation: Examples Using the NASA GEOS-5 LDAS, in: The Earth's Hydrological Cycle, edited by Bengtsson, L., Bonnet, R.-M., Calisto, M., Destouni, G., Gurney, R., Johannessen, J., Kerr, Y., Lahoz, W., and Rast, M., vol. 46 of Space Sciences Series of ISSI, pp. 577-606, Springer Netherlands, doi:10.1007/978-94-017-8789-5_6, http://dx.doi.org/10.1007/ 978-94-017-8789-5_6, 2014. 
Rudiger, C., Albergel, C., Mahfouf, J.-F., Calvet, J.-C., and Walker, J. P.: Evaluation of the observation operator Jacobian for leaf area index data assimilation with an extended Kalman filter, Journal of Geophysical Research: Atmospheres, 115, doi:10.1029/2009JD012912, http://dx.doi.org/10.1029/2009JD012912, d09111, 2010.

Schaap, M. G. and Leij, F. J.: Database-Related Accuracy and Uncertainty of Pedotransfer Functions, Soil Science, pp. 765-779, 1998.

Schneider, S., Wang, Y., Wagner, W., and Mahfouf, J.-F.: Impact of ASCAT soil moisture assimilation on regional precipitation forecasts: A case study for Austria, Monthly Weather Review, 142, 1525-1541, 2014.

Scipal, K., Drusch, M., and Wagner, W.: Assimilation of a ERS scatterometer derived soil moisture index in the ECMWF numerical weather prediction system, Advances in Water Resources, 31, 1101-1112, doi:10.1016/j.advwatres.2008.04.013, 2008.

Taylor, C., de Jeu, R., Guichard, F., Harris, P., and Dorigo, W.: Afternoon rain more likely over drier soils., Nature, 489, 423-426, 2012.

Timbal, B., Power, S., Colman, R., Viviand, J., and Lirola, S.: Does soil moisture influence climate variability and predictability over Australia?, Journal of Climate, 15, 1230-1238, 2002.

van Genuchten, M.: A closed-form equation for predicting the hydraulic conductivity of unsaturated soils, Soil Sci. Soc. Am. J, 44, 892-898, 1980.

Vereecken, H., Weynants, M., Javaux, M., Pachepsky, Y., Schaap, M., Genuchten, M. T., et al.: Using pedotransfer functions to estimate the van Genuchten-Mualem soil hydraulic properties: A review, Vadose Zone Journal, 9, 795-820, doi:10.2136/vzj2010.0045, 2010.

Vereecken, H., Huisman, J. A., Hendricks Franssen, H. J., Bruggemann, N., Bogena, H. R., Kollet, S., Javaux, M., van der Kruk, J., and Vanderborght, J.: Soil hydrology: Recent methodological advances, challenges, and perspectives, Water Resources Research, 51, 2616-2633, doi:10.1002/2014WR016852, http://dx.doi.org/10. 1002/2014WR016852, 2015.

Vinodkumar, and Dharssi, I., Bally, J., Steinle, P., McJannet, D., and Walker, J.: Verification of soil moisture from multiple models over Australia for fire danger rating application, Water Resources Research, Submitted, 2015.

Wagner, W., Hahn, S., Kidd, R., Melzer, T., Bartalis, Z., Hasenauer, S., Figa-Saldana, J., de Rosnay, P., Jann, A., Schneider, S., Komma, J., Kubu, G., Brugger, K., Aubrecht, C., Zuger, J., Gangkofner, U., Kienberger, S., Brocca, L., Wang, Y., Bloschl, G., Eitzinger, J., Steinnocher, K., Zeil, P., and Rubel, F.: The ASCAT Soil Moisture Product: A Review of its Specifications, Validation Results, and Emerging Applications, Meteorologische Zeitschrift, 22, 5-33, doi:doi:10.1127/0941-2948/2013/0399, http://www.ingentaconnect.com/ content/schweiz/mz/2013/00000022/00000001/art00002, 2013.

Walker, J. and Rowntree, P. R.: The effect of soil moisture on circulation and rainfall in a tropical model, Quarterly Journal of the Royal Meteorological Society, 103, 29-46, doi:10.1002/qj.49710343503, http://dx. doi.org/10.1002/qj.49710343503, 1977.

Weisheimer, A., Doblas-Reyes, F. J., Jung, T., and Palmer, T. N.: On the predictability of the extreme summer 2003 over Europe, Geophysical Research Letters, 38, doi:10.1029/2010GL046455, http://dx.doi.org/10. 1029/2010GL046455, 105704, 2011. 
635 Wu, L., Swan, J., Paulson, W., and Randall, G.: Tillage effects on measured soil hydraulic properties, Soil and Tillage Research, 25, 17 - 33, doi:http://dx.doi.org/10.1016/0167-1987(92)90059-K, http://www. sciencedirect.com/science/article/pii/016719879290059K, 1992. 

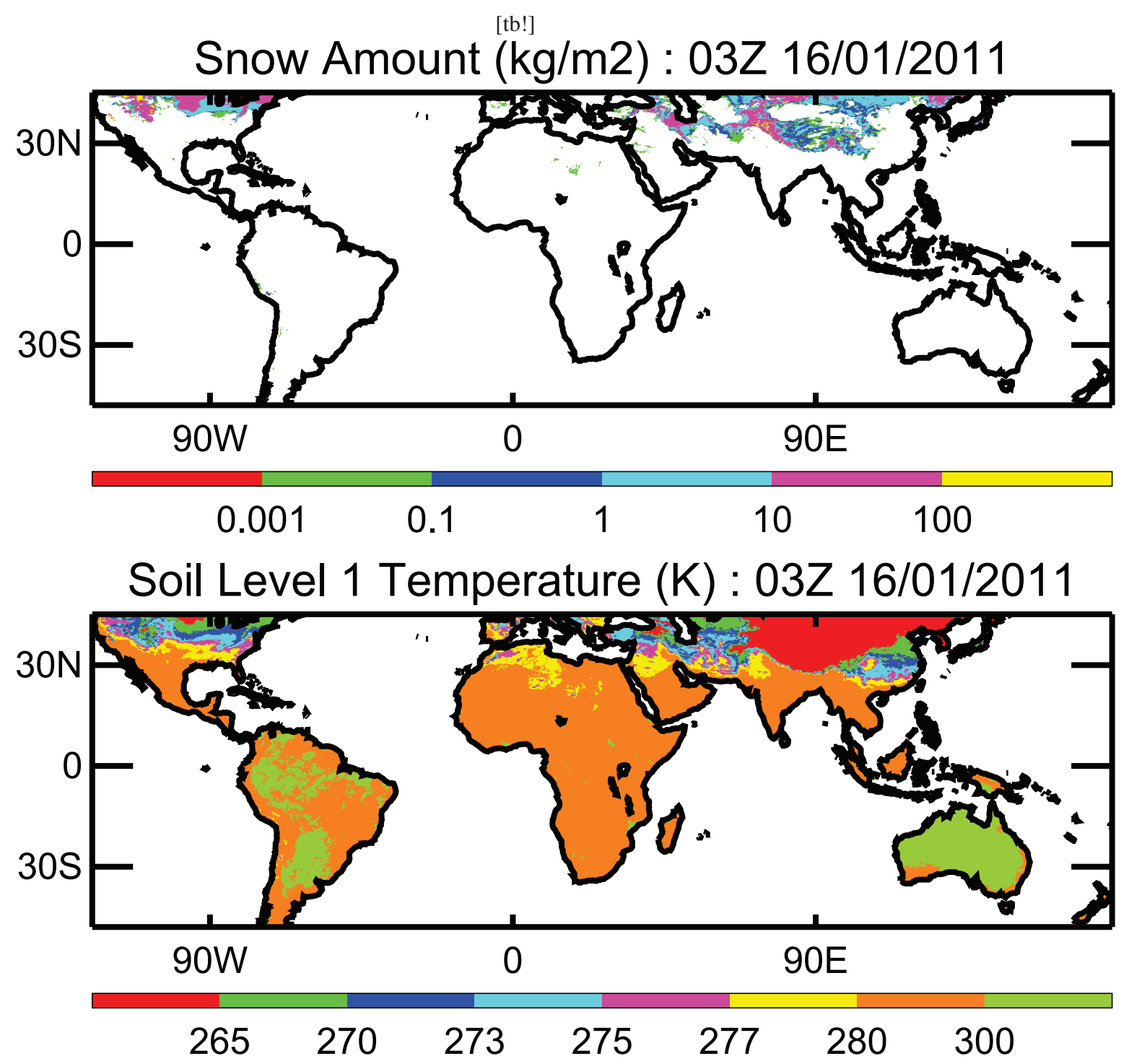

Figure 1. Initial conditions for model snow amount (top panel) and level 1 soil temperature (lower panel) at $3 Z$ 16/01/2011. 